\title{
Research on Vibration Performance of Stator End Winding in Large Steam Turbine-generator System
}

\author{
Zhang'ao Ren ${ }^{1, \text { a }}$ \\ ${ }^{1}$ Hunan Electrical Power Research Institute, Hunan 410000, China. \\ arenzando@foxmail.com
}

Keywords: Turbine-generator, vibration performance, stator end winding, axial constraint, hoop constraint.

\begin{abstract}
With the increase of the capacity of the generator, the electromagnetic force of the stator end winding of turbine-generator is increased, which can lead to the failure of the stator end winding. Based on this report, a finite element modeling method is proposed to solve the problem of complex structure modeling of turbine-generator stator end winding. The grid matching between electromagnetic and structural finite element model is realized. Meanwhile, the mechanical vibration performance of the turbine-generator stator end windings is analyzed by the method of the whole electromagnetic and local structure coupling simulation. The vibration performance of turbine-generator stator end winding under different reinforcement strategies are compared, and the preventive measures for the vibration fault of generator are explored.
\end{abstract}

\section{Introduction}

With the increase of turbine-generator capacity, the current of stator end winding is very large when it is running. Under the action of the rotating magnetic field, the stator end winding will bear a huge electromagnetic force [1, 2]. In the action of electromagnetic force, the stator end winding will produce a certain mechanical vibration $[3,4]$. When the stator end winding is the same as the natural frequency of the end winding structure, it will cause resonance [5].

Turbine-generator stator end winding structure is complex, which is involute shape distribution. Because of this special distribution, the calculation of electromagnetic force and the building of model is difficult at the winding end. With the increase of the capacity of the turbine-generator and the occurrence of the accident, the research on the calculation of the electromagnetic force and the vibration of the stator end winding is getting more and more attention[6].

Based on the finite element method, the mechanical vibration performance of the stator end winding of turbine-generator are analyzed. The vibration performance of turbine-generator stator end winding under different reinforcement strategies are compared, and the preventive measures for the vibration fault of generator are explored.

\section{Electromagnetic Field Theory}

In the field of static electric field, the electric field intensity $E$ satisfies the equation $\nabla \times \boldsymbol{E}=0$. As known by the vector analysis formula $\nabla \times(\nabla \varphi)=0$ and the scalar potential $\varphi$ is introduced to describe the characteristics of the electrostatic field, which is related to the intensity of electric field:

$$
\boldsymbol{E}=-\nabla \boldsymbol{\varphi}
$$

Where, a negative sign to show that the electric field intensity vector always points in the direction of the potential reduction rate is maximum.

By using the electrostatic field equations $\boldsymbol{D}=\varepsilon \boldsymbol{E}$ and $\nabla \cdot \boldsymbol{D}=\varepsilon$, the equations (2) and (3) can be deduced:

$$
\begin{aligned}
\nabla \cdot \boldsymbol{D} & =\varepsilon \\
\nabla \cdot \boldsymbol{E} & =\rho
\end{aligned}
$$

Where, $D$-electric flux density vector $\left(\mathrm{C} / \mathrm{m}^{2}\right) ; \varepsilon$-dielectric constant ( $\left.\mathrm{F} / \mathrm{m}\right) ; \rho$ - charge density $\left(\mathrm{C} / \mathrm{m}^{3}\right)$. 


\section{Simulation Method}

\subsection{Geometric Model}

Generator stator end winding structure is relatively complex, and the end winding is gradually open in the space, which is difficult to build the geometric model of ANSYS. The third party software Solidworks is used to build the model of generator. Fig. 1 shows the main part of the winding and the stator geometry model.

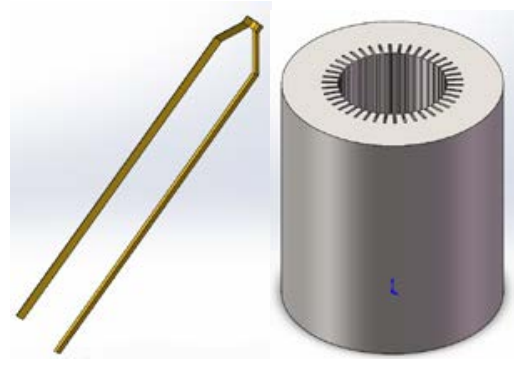

Fig.1 Winding and the stator geometry model

\subsection{ANSYS Model}

After the Solidworks modeling is built, the model is needed to import the ANSYS for the electromagnetic field and structure coupling analysis. Then, the air gap and the surrounding air region are established.

After the geometric model is finished, the mesh of the model is needed. In the model, due to the complicated geometry, hexahedral meshing is difficult to be used. As a result, the tetrahedral mesh is used in the model. In the process of dividing, since the complex shape and larger magnetic field distribution in the winding, the mesh of the air gap and the air region where contact with the winding needs to be carefully divided.

\subsection{Material Parameters and Load}

For ferromagnetic materials, the material properties are set up by setting the corresponding $\mathrm{BH}$ curve. For the conductor material, the resistivity of copper is set up, and the relative permeability is set to 1 . For air material, the relative permeability is 1 .

In this paper, a phase current which is the maximum limit is selected. When the load is applied, the A phase current is applied to the maximum current $20 \mathrm{kA}$, the B phase current is applied to the $10 \mathrm{kA}$, and the $\mathrm{C}$ phase current is applied to the $-10 \mathrm{kA}$.

\section{Vibration Performance of Stator End Winding with Electromagnetic Force}

\subsection{Vibration Analysis of Stator End Winding under Axial Restraint}

Fig. 2 shows the stator end winding three modal shapes in the axial constraint state. The results show that the vibration of the stator end winding is more similar to that of the vibration of free state, but the excitation frequency increased significantly, reaching $276.4 \mathrm{~Hz}$. The vibration frequency of the stator end winding under axial constraint is $276.4 \mathrm{~Hz}, 345.3 \mathrm{~Hz}$, and $514.8 \mathrm{~Hz}$, respectively.

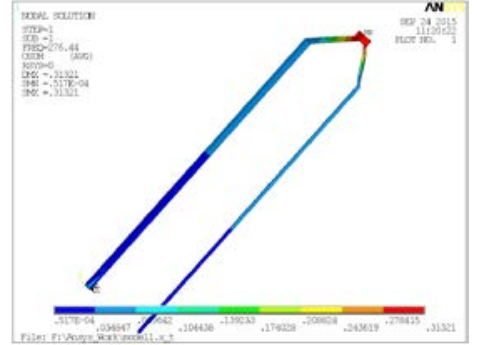

(a)first order mode

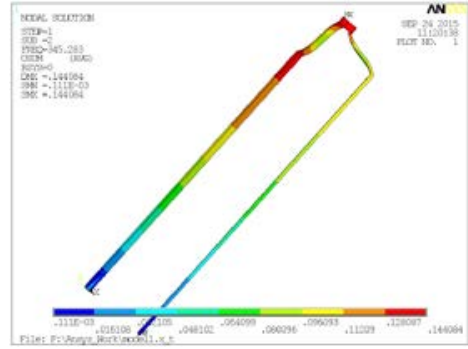

(b) second order mode

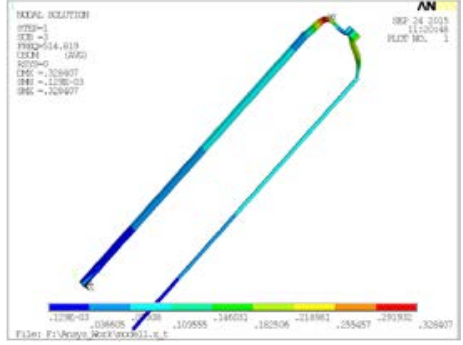

(c) third order mode

Fig. 2 The stator end three modal shapes in the axial constraint state

Furthermore, the vibration of the stator end winding under electromagnetic force excitation is studied in the axial constraint state. The results are shown in Fig. 3 when the electromagnetic force frequency is $100 \mathrm{~Hz}, 150 \mathrm{~Hz}$ and $200 \mathrm{~Hz}$, respectively. The maximum displacement of the stator end 
is $0.32 \mathrm{~mm}, 0.38 \mathrm{~mm}$ and $0.55 \mathrm{~mm}$, respectively. The vibration of the stator end is similar to the first modal shape of the stator end winding. Meanwhile, because $200 \mathrm{~Hz}$ is the most close to the first modal shape vibration frequency of the stator end winding, $276.4 \mathrm{~Hz}$, the vibration displacement of $200 \mathrm{~Hz}$ is the largest.

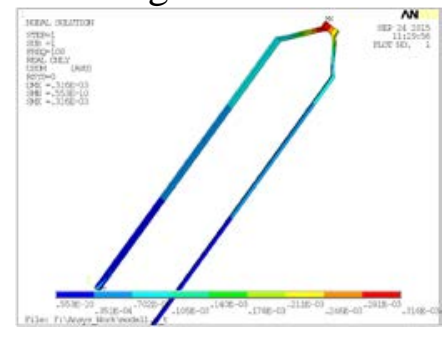

(b) $100 \mathrm{~Hz}$

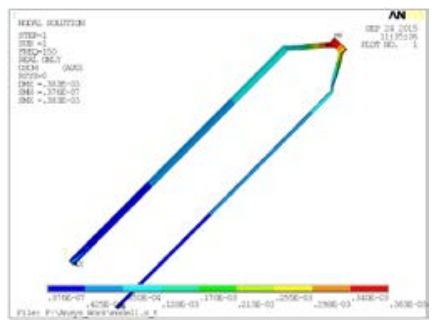

(c) $150 \mathrm{~Hz}$

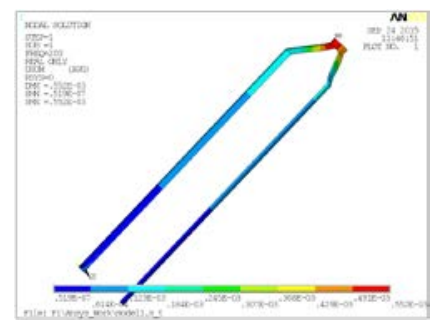

(d) $200 \mathrm{~Hz}$

Fig.3 The stator end winding corresponding to different frequency electromagnetic force loads under axial restraint (a) $100 \mathrm{~Hz}$; (b) $150 \mathrm{~Hz}$; (c) $200 \mathrm{~Hz}$

\subsection{Vibration Analysis of Stator End Winding under Hoop Constraint}

Fig. 4 shows three modal shapes of the stator end winding in the hoop constraint state. The results show that there are some differences between the vibration of the stator end winding under hoop constraint and the vibration of the stator end winding under free state, and the vibration frequency of the stator is increased obviously. The vibration frequency of the stator end winding under hoop constraint is $325.7 \mathrm{~Hz}, 353.4 \mathrm{~Hz}, 453.4 \mathrm{~Hz}$, respectively.

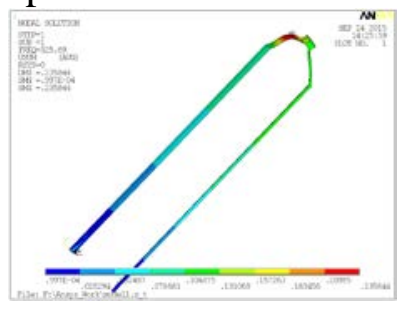

(a) first order mode

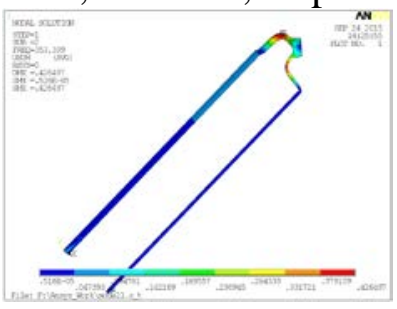

(b) second order mode

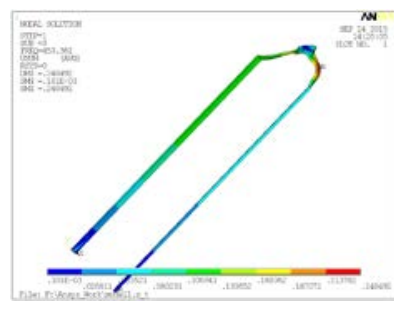

(c) third order mode

Fig. 4 The stator end three modal shapes in the hoop constraint state

Furthermore, the vibration of the stator end under electromagnetic force excitation is studied in the hoop constraint state. The results are shown in Fig. 5. When the electromagnetic force frequency is $100 \mathrm{~Hz}, 150 \mathrm{~Hz}$ and $200 \mathrm{~Hz}$, respectively, the maximum displacement of the stator end is $0.19 \mathrm{~mm}$, $0.21 \mathrm{~mm}$ and $0.26 \mathrm{~mm}$, respectively. The vibration of the stator end is similar to the first modal shape of the stator. Meanwhile, because $200 \mathrm{~Hz}$ is the most close to the first modal shape vibration frequency of the stator, $325.7 \mathrm{~Hz}$, the vibration displacement of $200 \mathrm{~Hz}$ is the largest.

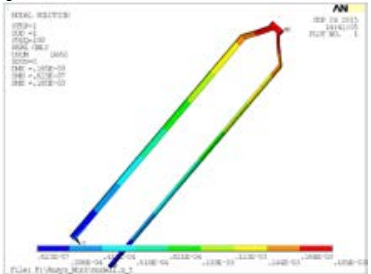

(a) $100 \mathrm{~Hz}$

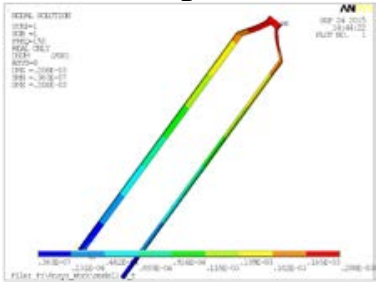

(b) $150 \mathrm{~Hz}$

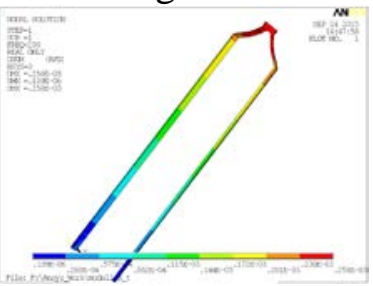

(c) $200 \mathrm{~Hz}$

Fig. 5 The stator end corresponding to different frequency electromagnetic force loads under hoop restraint (a) $100 \mathrm{~Hz}$; (b) $150 \mathrm{~Hz}$; (c) $200 \mathrm{~Hz}$

In general, the axial constraint can improve the natural frequency of the stator winding, but because of the limit of axial displacement, the vibration displacement of the stator end is greater. For the loop constraint, the vibration displacement of the stator end can be reduced effectively. Therefore, in practice, the main method to reduce the vibration of the stator end winding is the loop constraint. 


\section{Conclusion}

In this paper, the problem of modeling complex structure of the stator end winding of turbine-generator is solved by the grid mapping technique. The whole electromagnetic and local structure coupling simulation method is used to analyze the mechanical vibration performance of the stator end winding of turbine-generator. Although the axial constraint can improve the natural frequency of the stator end winding, however, because of the limitation of the axial displacement, the vibration displacement of the stator end winding is greater. For the loop constraint, it can effectively reduce the vibration displacement of the stator end. Therefore, loop constraint can be used to reduce the vibration of stator end winding.

\section{References}

[1]. HU Yuda, QIU Jiajun, QING Guanghui. electromagnetic vibration of integrity end winding of large turbo-generator stator. Proceedings of the CSEE. Vol.23(2003) No.7, p.93-98,116.

[2]. Wu Yongxia, ZHANG Jia, LIANG Xubiao, etal. Numerical calculation of transient eddy current fields and electromagnetic forces acting on end winding of large turbogenerators. Journal of mechanical \& electrical engineering. Vol.29(2012) No.3, p.249-252.

[3]. LIU Shi, ZHONG Jize, FENG Yongxin, etal. Magneto Rheological Technology of Vibration Isolation for Stator End-Winding of Large Generators. Journal of Xi'an Jiaotong University. Vol.47(2013) No.4, p.39-43.

[4]. LIU Mingdan, LIU Nian. Electrodynamic force calculation and vibration analysis of the end winding of turbo-generators. Automation of electric power systems. Vol.29(2005) No.15, p.40-44.

[5]. YANG Qunfa, SHEN Wenhua, LIU Shi. Comprehensive treatment of end vibration in turbine generator stator. Thermal Power Generation. Vol.44(2015) No.5, p.125-128.

[6]. CHEN Weiliang, XU Bohou, HUANG Lei. Vibration analysis of stator winding end baskets of large turbo-generator. Journal of Zhejiang University (Engineering Science). Vol.44(2010) No.8, p.1558-1561. 